\title{
Comparison of centchroman and PPIUCD in terms of efficacy, safety and continuation rate in immediate postpartum period
}

\author{
Megha Gupta*, Reeta Bansiwal, H. P. Anand
}

Department of Obstetrics and Gynecology, VMMC and Safdarjung Hospital, Delhi, India

Received: 07 October 2020

Revised: 15 November 2020

Accepted: 01 December 2020

\author{
*Correspondence: \\ Dr. Megha Gupta, \\ E-mail: megha.gupta395@gmail.com
}

Copyright: (c) the author(s), publisher and licensee Medip Academy. This is an open-access article distributed under the terms of the Creative Commons Attribution Non-Commercial License, which permits unrestricted non-commercial use, distribution, and reproduction in any medium, provided the original work is properly cited.

\begin{abstract}
Background: Study was done to assess the efficacy, safety and continuation rate of Centchroman and IUCD administered in immediate postpartum period (within 48 hours).

Methods: An interventional study was conducted in Obstetrics and Gynecology department of Safdarjung Hospital, New Delhi, at a tertiary care hospital after approval from ethical committee. 280 women were enrolled in the study and divided into 2 groups centchroman group and PPIUCD group, 140 in each group after excluding the exclusion criteria and satisfying inclusion criteria. These women were followed up at 6 week, 3 month and 6 months to study efficacy, safety and continuation rate.

Results: Centchroman as contraception is safe with fewer side effects, better satisfaction rate and better continuation rate in comparison to PPIUCD.

Conclusions: Centchroman is a newer contraceptive which is recently added in basket of family planning in our country to give wider choices to women. It is an indigenous product developed by central drug research institute (CDRI), Lucknow available free of cost in government hospitals. Centchroman needs more popularity and education for its widespread use.
\end{abstract}

Keywords: Centchroman, Continuation rate, PPIUCD, Safety, Satisfaction rate

\section{INTRODUCTION}

India is second largest populated country of the world with 120 million according to 2011 census. ${ }^{1}$ It contributes $17.5 \%$ of world's population by adding around 25 million births every year. ${ }^{2}$ Hence a great need of contraception, ways to prevent unwanted pregnancy by temporary or permanent method.

In the first year following delivery, $65 \%$ of women are having unmet need of family planning. ${ }^{3}$ Lack of information and fear of complication are the most common reason for this unmet need. Even though India has made considerable progress in reducing maternal mortality rate (MMR), it still contributes to $20 \%$ of world maternal death. ${ }^{2}$ It has been reported that over $60 \%$ of maternal death occurring in developing countries, occur within first year of delivery. ${ }^{4}$

Postpartum period is the most receptive period for the women and family to accept contraception and with increase in institutional deliveries influenced by Janani Suraksha Yojana (JSY). The contact of women after childbirth in the first 48 hours with the health care provider is an opportunity to counsel and provide them with safe and appropriate contraceptive methods of their choice before they leave for home. ${ }^{4}$

India was the first country in the world to have launched a National Programme for Family Planning in 1952. In 
spite of all programs, India still has the women with largest unmet needs of contraception (13\%) (>20\%of women in Nagaland, Jharkhand, Bihar, and Uttar Pradesh). ${ }^{1}$

On 5th September 2017, Centchroman was added to the basket of contraceptives with the name of "Chhaya" and available free of cost in medical colleges and in 10 districts of India. ${ }^{5}$

It is a safe and reliable oral contraceptive agent ideally suited for spacing of birth in women who have no major medical contraindications. Centchroman creates an asynchrony between development of embryo and uterine endometrium development and thus preventing the pregnancy. 6 Whereas Postpartum intra uterine contraceptive device (PPIUCD) on the other hand is onetime contraceptive measure acts by creating an inflammatory response in the endometrium and thus an adverse environment for the sperms and zygote. ${ }^{7}$

There is no Indian study which compared these two agents of contraceptives, so this study was planned to compare Centchroman and PPIUCD in terms of efficacy and safety.

\section{METHODS}

This interventional study was conducted in Obstetrics and Gynecology department of Vardhman Mahavir Medical College and Safdarjung hospital, a tertiary care hospital after approval from institutional ethical committee from November 2017 to December 2018.

Total 280 women were enrolled in the study after fulfilling the inclusion and exclusion criteria and divided into 2 groups. Centchroman group and PPIUCD group, 140 in each group. All women of 20-40 years of age group delivering in Safdarjung Hospital were included in the study. Women with severe anemia, prolonged rupture of membrane of more than 18 hour, distorted uterine cavity, postpartum hemorrhage, recent h/o pelvic tuberculosis, recent h/o pelvic inflammatory disease, HIV/AIDS, recent history of jaundice and liver disease, allergy to Centchroman/Copper and medical disorder such as Diabetes Mellitus/Hypertension/Heart disease/ Renal disease/Liver disease were excluded from the study. Immediately post-partum vaginal delivery/cesarean (with 48 hours) women were counselled for the PPIUCD and Centchroman and those who were willing for both were randomized into two groups by block randomization with sealed envelope system. PPIUCD $(\mathrm{Cu} 380 \mathrm{~A} / 375)$ was inserted intrauterine immediately post placental or within 48 hours post-delivery. Centchroman was given $30 \mathrm{mg}$ orally within 48 hours of delivery and then twice weekly for 3 months followed by once a week. These women were followed at 6 weeks, 3 months and 6 months postpartum and were assessed in terms of safety, efficacy and continuation rate.

\section{Statistical analysis}

Categorical variables were presented in number and percentage $(\%)$ and continuous variables were presented as mean \pm SD and median. Normality of data was tested by Kolmogorov-Smirnov test when the normality was rejected then non parametric test was used. Quantitative variables were compared by Unpaired t-test/MannWhitney Test (when the data sets were not normally distributed) between the two groups. Qualitative variables were compared using Chi-Square test /Fisher's exact test. The data was assessed using Statistical Package for Social Sciences (SPSS) version 21.0.

\section{RESULTS}

The mean age of women was comparable in both the groups. The youngest women in both the groups was of age 21 years. Eldest women in centchroman group was of age 34 years and PPIUCD was of 35 years.

At 3 months and 6months women were more satisfied in the centchroman group in comparison to PPIUCD group though the results were not statistically significant $(138 / 140,135 / 140 ; 133 / 140,131 / 140)$. The main reason for dissatisfaction among centchroman group was lack of motivation in $3.57 \%$, menstrual irregularity in $0.71 \%$ women and gastritis in 0.71 . The main reason for dissatisfaction among PPIUCD user was lower abdomen pain in $3.57 \%$ female followed by menstrual irregularity in $1.43 \%$ women followed by vaginal discharge and psychosocial issue seen in $0.71 \%$ women (Figure 1).

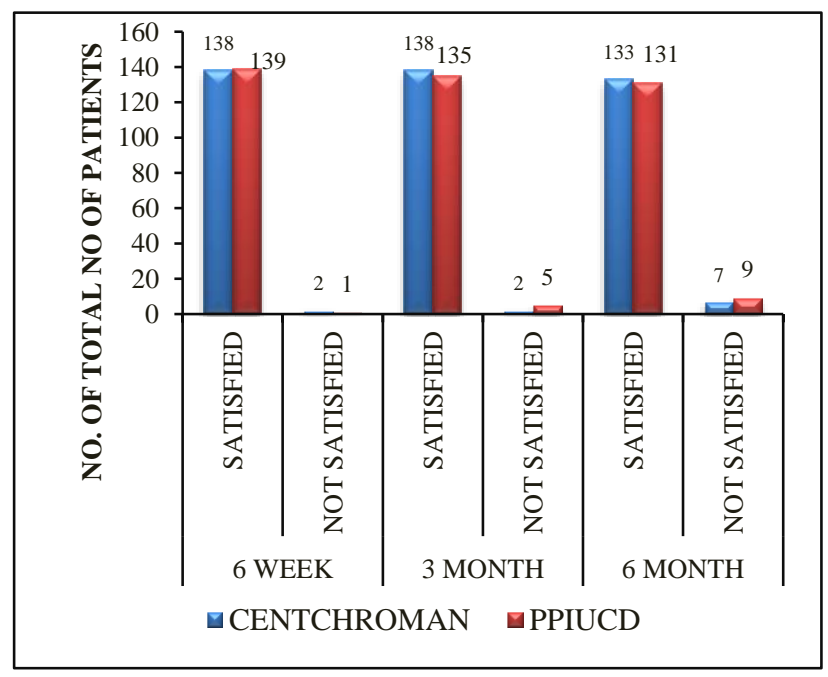

Figure 1: Satisfaction rate.

As far as safety is concerned both Centchroman and PPIUCD are safe with minor menstrual irregularities in both. Oligomenorrhoea was more common menstrual irregularity in centchroman group (14/140 (10\%)) and menorrhagia was main complaint in PPIUCD group $(15 / 140(10.7 \%))$ (Figure 2). 


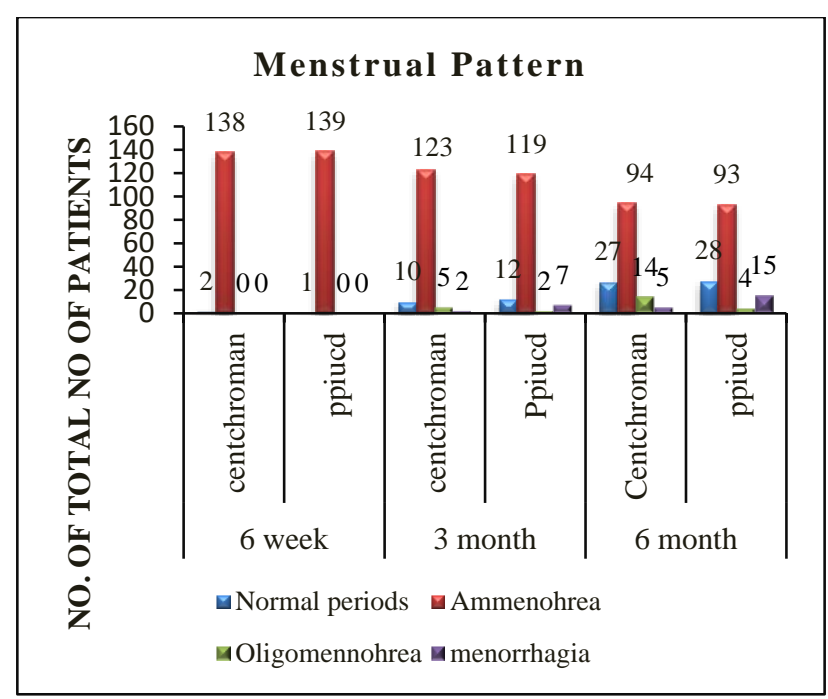

Figure 2: Variation in menstrual pattern.

No other significant side effect like raised BP, headache, mood changes, breast discomfort, endometrial change on USG or adenxal pathology was seen in either of the groups. Spontaneous expulsion of PPIUCD occurred in 2 women at 6 weeks, 6 women at 3 month and 7 women at 6 month respectively. There was no case of perforation in PPIUCD users (Table 1).

Table 1: Side effects.

\begin{tabular}{|c|c|c|c|}
\hline \multicolumn{2}{|l|}{ Side effect } & Centchroman & PPIUCD \\
\hline \multicolumn{2}{|c|}{ Nausea/vomiting } & 0 & 0 \\
\hline \multicolumn{2}{|c|}{ Mood changes } & 0 & 0 \\
\hline \multicolumn{2}{|l|}{ Headache } & 0 & 0 \\
\hline \multicolumn{2}{|l|}{ Raised BP } & 0 & 0 \\
\hline \multirow{2}{*}{$\begin{array}{l}\text { Most } \\
\text { common } \\
\text { Menstrua } \\
\text { l pattern }\end{array}$} & Oligomennohrea & $10 \%$ & $2.86 \%$ \\
\hline & Menorrhagia & $3.57 \%$ & $10.71 \%$ \\
\hline \multicolumn{2}{|c|}{$\begin{array}{l}\text { USG abnormality in uterus } \\
\text { and adenaxe }\end{array}$} & 0 & 0 \\
\hline
\end{tabular}

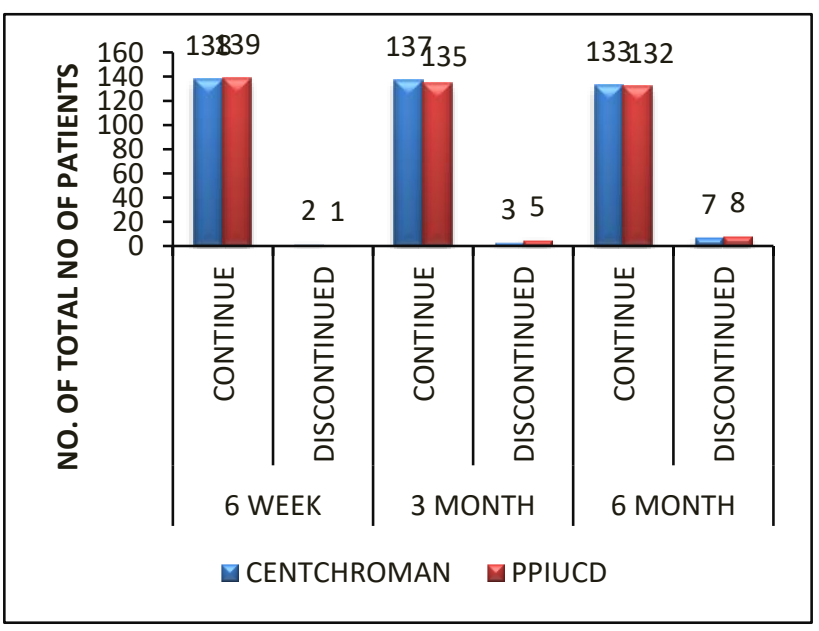

Figure 3: Continuation rate.
The failure rate was $0 \%$ in both the groups at 6 months. Continuation rate was more in Centchroman users in comparison to PPIUCD users at the end of 6 months (128/140 (91.4\%; 126/140 (90\%), p=1.0) (Figure 3). The main reason for continuation in Centcroman were oral intake, non-hormonal nature.

At 6 month discontinuation rate in PPIUCD and centchroman group were comparable (8/140 (5.7\%), $7 / 140(5 \%) ; \mathrm{p}=0.7))$.

\section{DISCUSSION}

Reversible, long term contraception is the need of every immediate postpartum woman. Earlier there was only PPIUCD which was available in the basket of family planning for immediate postpartum contraception. With the availability of a non- hormonal, oral drug for contraception under the umbrella of family planning is the boom for patients. In our study we also find the same as the continuation rate was more in the centchroman group then PPIUCD group though not statistical significant.

According to a prospective study by Nair et al, Centchroman is a safe nonsteroidal contraceptive. Menstrual complaint was noted in $45 \%$ of subject delayed cycle in $26 \%$ and scanty flow in $1 \%$ which was the major reason for its discontinuation in 6 patient. Other causes were inability to come for follow up in $1 \%$ and desire to conceive in $2 \%{ }^{6}$

In our study the most common side effect associated was menstrual irregularity. At the end of 6 months heavy menstrual bleeding (menorrhagia) was seen in $10.71 \%$ women in PPIUCD group and whereas oligomennohrea was seen mainly centchroman $(10 \%)$ group.

Similar results were found by Aggarwal et al, the most common adverse drug reaction with centchroman use was menstrual irregularity in their study. After 6 month of therapy, $10(40 \%)$ women present with this complaint, 2 (8\%) had short menstrual cycle $<20$ days, 4 (16\%) had cycle $>45$ days and $4(16 \%)$ had developed amenorrhea. ${ }^{8}$

Similar results seen in Nair et al study with oligomenorrhoea in $26 \%$ women and hypomenorrhea in $1 \% .{ }^{6}$ Celen et al showed the main side effect of IUCD usage are prolonged and excessive bleeding and abdominal pain during menstruation and reported rate of removal due to bleeding/pain was 3.3 per 100 women/year. ${ }^{9}$

In our study no other side effect like nausea, vomiting, mood changes, raised BP, breast discomfort uterine and adnexal abnormality was present in either of the two groups. Expulsion rate of PPIUCD was 0. Failure rate of centchroman and PPIUCD was 0 . 
As far as satisfaction is concerned more women were satisfied in centchroman group due to lack of major side effects and oral intake than PPIUCD group though not statistically significant. (133 (95.23\%), $131(93.57 \%))$ at end of 6 months.

Most common reasons for dissatisfaction in centchroman group were lack of motivation followed by menstrual irregularity and gastritis whereas pain lower abdomen followed by menstrual irregularity followed by vaginal discharge and psychosocial issue were there in PPIUCD group.

Balara et al, in their study also found the main reason for dissatisfaction of PPIUCD as vaginal bleeding and pain abdomen in $3 \%$ of women. Missing strings was complained by $8 \%$ of women. ${ }^{10}$

\section{CONCLUSION}

Centchroman as contraception is safe with fewer side effects and has better satisfaction rate and better continuation rate in comparison to PPIUCD.

\section{Limitation}

There was less sample size and less follow up due to time constrain in this study. Therefore more sample size is needed to have statistical significant differences between the two modalities of contraception.

\section{Funding: No funding sources}

Conflict of interest: None declared

Ethical approval: The study was approved by the Institutional Ethics Committee

\section{REFERENCES}

1. India at Glance Population census 2011. Census organization of India, 2011. Available at http:// censusindia.gov. in/ 2011-prov- results /india at glance. html. Accessed on 25 August 2017.
2. IUCD reference manual for medical officers and nursing personal: Family Planning Division, Ministry of Health and Family Welfare, Government of India 2013. Available at http:// www. nrhmtn. gov.in/modules/IUCD_Reference_Manual_for_MOs _and_Nursing_Personne_-Final-Sept_2013:1-15. Accesed on 20 August 2017.

3. Park K. Social and Preventive Medicine. 23rd ed. Jabalpur: Banarsidas bhanot; 2015:437-440.

4. Counselling for postpartum family planning and immediate postpartum iucd reference manual 2011. Available at http:// reprolineplus. org/ system/ files/resources/PPFP_PPIUCD_Counseling_Manual _draft. chapter $1: 1-\overline{8}$. Accessed on 15 September 2017.

5. Kamboj VP, Ray S, Anand N. Centchroman: a safe reversible postcoital contraceptive with curative and prophylactic activity in many disorders. Frontiers Biosci Elite. 2018;10:1-14.

6. Nair HS, Jayasimhan P. A prospective study of centchroman users with special reference to its contraceptive benefit. J Evid Based Med Healthc. 2016;3:5374-80.

7. Smith J, Muthoni J, Das V. International conference on family planning: research and best practice. 2009:15-18.

8. Agrawal P, Kushwa V, Mangal BK. Evaluation of safety profile of centchroman for contraceptive purpose. National J Allied Sci. 2016;5:41-4.

9. Celen S, Moroy P, Sucak A, Aktulay A, Danisman N. Clinical outcome of early post placental insertion of intrauterine contraceptive devices. Contraception. 2004;69:279-82.

10. Barala S, Maheshwari S, Sharma P. Analysis of awareness, acceptance, safety and continuation rate of post-placental and intra-caesarean insertion of intrauterine contraceptive device. Int $\mathbf{J}$ Reprod Contracept Obstet Gynecol. 2016;5:1974-80.

Cite this article as: Gupta M, Bansiwal R, Anand HP. Comparison of centchroman and PPIUCD in terms of efficacy, safety and continuation rate in immediate postpartum period. Int J Reprod Contracept Obstet Gynecol 2021;10:203-6. 